\title{
Experimental Investigation on Performance of Fouling Prediction Devices for NF/RO System
}

\author{
C. H. Koo, A. W. Mohammad, and F. Suja'
}

\begin{abstract}
The performance of fouling prediction devices (i.e. modified fouling index and crossflow sampler-modified fouling index) operating under constant flux mode for reverse osmosis (RO)/nanofiltration (NF) filtration system was investigated experimentally. The effect of crossflow hydrodynamic, foulant concentration, foulant particle sizes, and membrane resistance were investigated correspond to MFI $_{\text {const.flux. Three types of }}$ foulants (i.e. $70-100 \mathrm{~nm}$ colloidal silica, $22 \mathrm{~nm}$ colloidal silica, Aldrich humic acid) were adopted. The results showed that the MFI $_{\text {const.flux values were higher than CFS-MFI }}$ const.flux, particularly for high polydispersed foulants (i.e. 70-100 nm colloidal silica and Aldrich humic acid). The MFI $_{\text {const.flux }}$ values were consistently increased with increasing foulant concentration and membrane resistance. Higher values of MFI $_{\text {const.flux }}$ were observed for polydispersed foulant (i.e. 70-100 $\mathrm{nm}$ colloidal silica) than monodispersed foulant (i.e. $22 \mathrm{~nm}$ colloidal silica). This study yielded useful insights in understanding the crossflow effect, foulant concentration, foulant particle sizes, and membrane resistance on the RO/NF fouling potential.
\end{abstract}

Index Terms-Colloidal silica, constant flux, crossflow, humic acid, ultrafiltration.

\section{INTRODUCTION}

Conventional membrane fouling prediction tools are Silt density index (SDI) and Modified Fouling Index (MFI). SDI is particularly common in the industry for predicting the colloidal fouling potential of feed in RO/NF membranes following its simplicity in operation [1]. However, derivation of SDI was not founded on any fouling mechanisms and this factor appears to be the main drawback of the SDI to perform as an appropriate indicator for RO membrane fouling [2], [3]. On the other hand, the MFI has relatively good correlation with the feed concentration and thus, it can be used to represent the actual fouling behaviour of feed [4], [5]. Although the MFI is found greatly linear with the concentration of feed, the conventional MFI test is designed to perform in dead-end filtration mode while most RO systems are operated under crossflow filtration mode [6]. Consequently, the operation of MFI test is completely

Manscript received May 29, 2014; revised September 28, 2014. This work was supported by Ministry of Higher Education Malaysia under the grant of Top-Down Long Term Research Grant Scheme through project no. 4L804.

C. H. Koo is with Faculty of Engineering and Science, Universiti Tunku Abdul Rahman, Jalan Genting Kelang, 53300 Setapak, Kuala Lumpur, Malaysia (e-mail: kooch@utar.edu.my).

A. W. Mohammad and F. Suja' are with Faculty of Engineering and Built Environment, Universiti Kebangsaan Malaysia, 43600 UKM Bangi, Selangor, Malaysia (e-mail: wahabm@eng.ukm.my, fati@eng.ukm.my). different from the filtration process of RO [7]-[9]. To create similarity between the MFI test and the RO filtration process, a crossflow sampler-modified fouling index (CFS-MFI) that operates under crossflow conditions was developed by Javeed et al. [7], [9]. In the CFS-MFI device, a CFS cell is placed at upstream while the standard MFI device is installed at downstream. A macrofilter is installed in the CFS cell to create the crossflow hydrodynamic effect as demonstrated in the RO filtration process. The macrofilter in CFS usually allows finer particles to pass through so that they can possibly deposit on the $0.45 \mu \mathrm{m}$ membrane placed in the dead-end standard MFI $\left(\mathrm{MFI}_{0.45}\right)$. It was found that the standard MFI values were overestimated compared to the CFS-MFI due to lack of CFS cell [6], [10]. Types of membranes adopted in the dead-end standard MFI could also greatly affect the value of MFI. Boerlage et al. [11] adopted ultrafiltration (UF) membranes with different molecular weight cut-off (MWCO) to measure the MFI under constant pressure mode. They revealed that higher value of MFIUF was obtained when UF membranes with lesser MWCO were adopted. Despite the fact that the MFI device has been widely used for predicting $\mathrm{RO} / \mathrm{NF}$ fouling, there are not many studies associated with the effect of crossflow hydrodynamic, foulant concentration, foulant particle sizes, and membrane resistance on the values of MFI.

In this study, the effect of crossflow hydrodynamic, foulant concentration, foulant particle sizes, and membrane resistance were investigated using the MFI devices. The devices are instrumented to monitor transmembrane pressure (TMP), crossflow velocity, and flux at a desired time interval.

\section{SET-UP OF Fouling PREDICTION DEVICES}

The schematic diagram of the equipments used for the $M \mathrm{MI}_{\text {const.flux }}$ and CFS-MFI $\mathrm{const.flux}_{\text {tests }}$ is shown in Fig. 1. The fouling index (FI) measuring device comprises of feed and collection tanks, a feed pump, a CFS cell (SEPA CF, GE Osmonics $\odot$, Minnetonka, MN), flowmeters, pressure gauges, pressure sensors, a peristaltic pump, a dead-end cell, an electronic balance, and data logging system. The effective membrane areas of CFS cell and dead-end cell were 0.0155 $\mathrm{m}^{2}$ and $0.0095 \mathrm{~m}^{2}$, respectively. To differentiate between $\mathrm{MFI}_{\text {const.flux }}$ and CFS-MFI const.flux $_{\text {, a non-retentive membrane }}$ filter with straight-through pores $(5 \mu \mathrm{m} \mathrm{MF})$ was placed in

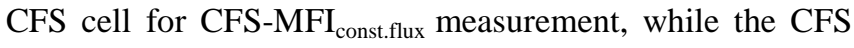
cell was left empty (no membrane) for the measurement of

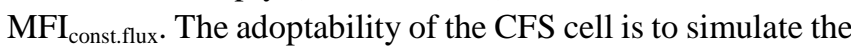
crossflow filtration effect in the FI measuring devices as in RO system [6], [7]. Pressure sensors were used to gauge the TMP increase in the MFI cell (dead-end cell). The readings of 
the pressure sensors at the dead-end cell were continuously recoded in the data logging system.

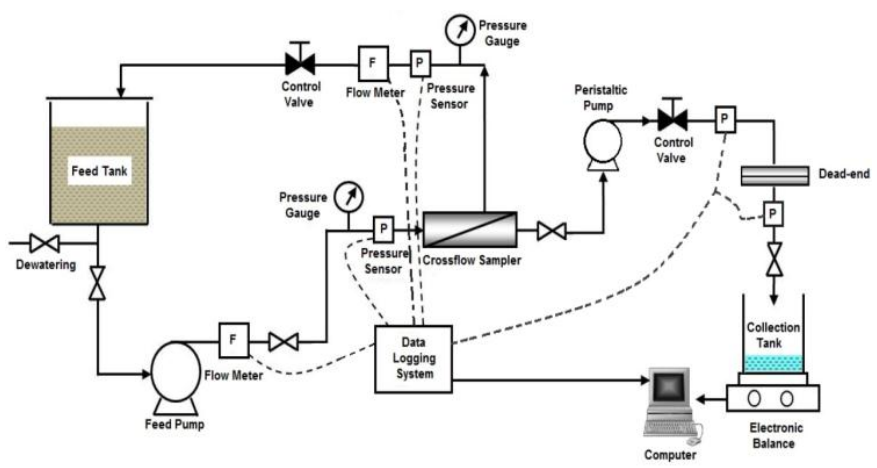

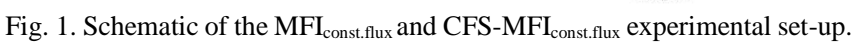
Reprinted from [21] with permission from Elsevier.

\section{TESTING DeVICES}

\section{A. Experimental Procedures}

In this study, the peristaltic pump was installed in the CFS permeate stream to withdraw permeate from the CFS cell and subsequently delivered the flow to the dead-end cell. The constant flux in the dead-end cell was fixed at $30.9 \mathrm{~L} / \mathrm{m}^{2} \mathrm{~h}$.

A constant crossflow rate of $3.2 \mathrm{~L} / \mathrm{min}$ was maintained in the channel of crossflow cell, which corresponds to the crossflow velocity of $0.39 \mathrm{~m} / \mathrm{s}$. The crossflow velocity selected was in the range of typical crossflow velocities adopted in common RO membrane processes [8]. All fouling runs subjected to $\mathrm{MFI}_{\text {const.flux }}$ and $\mathrm{CFS}-\mathrm{MFI}_{\text {const.flux }}$ measurements were tested with various types of foulant under the same operating conditions. Table I summarizes parameter values used for each run in this study. All filtration experiments were conducted at room temperature of about $25^{\circ} \mathrm{C}$ and repeated for at least twice to ensure the results were reproducible.

\section{B. Synthetic Solutions}

Three types of foulants (i.e. 70-100 nm colloidal silica, 22 $\mathrm{nm}$ colloidal silica, Aldrich humic acid) were adopted in this study. The colloidal silica was chosen to represent the colloidal types of foulant, while the Adrich humic acid is organic type. The model foulants for colloidal silica of 70-100 nm (ST-XL) and $22 \mathrm{~nm}$ (LUDOX-TM50) were supplied by Nissan Chemicals and Sigma Aldrich, respectively. The foulant solutions of colloidal silica were prepared by adding a buffer solution to obtain the desired concentration (i.e. 0, 50, 100, and $200 \mathrm{mg} / \mathrm{L}$ ). The buffer solution was prepared by mixing $6.81 \mathrm{~g}$ of potassium dihydrogen phosphate $\left(\mathrm{KH}_{2} \mathrm{PO}_{4}\right)$ with $467 \mathrm{ml}$ of $0.1 \mathrm{M}$ sodium hydroxide $(\mathrm{NaOH})$ to produce a feed solution of $\mathrm{pH} 8$ [8]. The function of buffer solution is to help in enhancing the solubility of colloidal silica in the feed solution. The solubility of colloidal silica increases proportionally with $\mathrm{pH}$ when the $\mathrm{pH}$ is greater than 7.8 [12]. The mixture of solution was then exposed to sonication treatment for duration of 10 min to ensure that the solution was stable and free from any large aggregates [13].

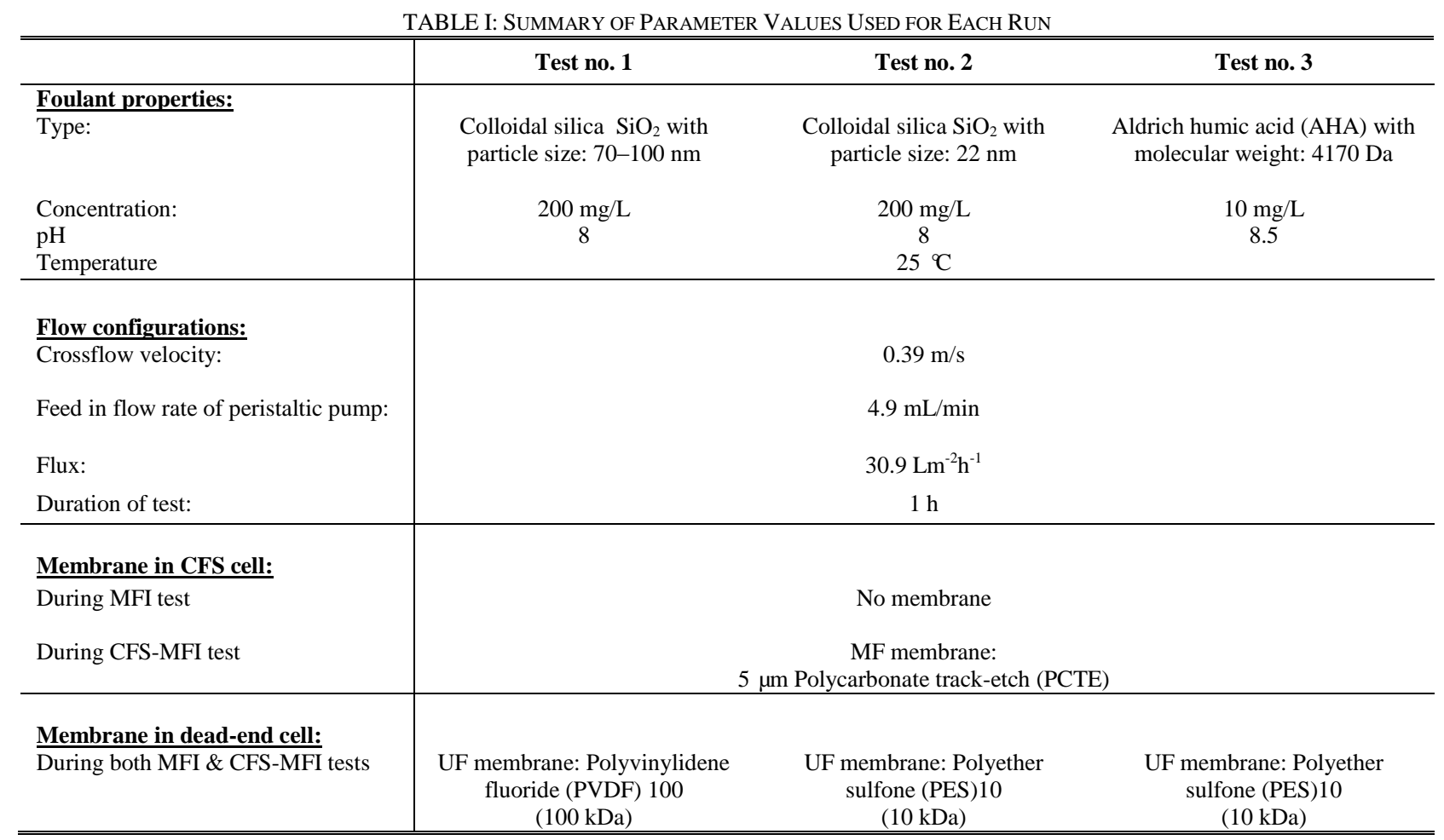

Commercial type of AHA with apparent molecular size of 300-10,000 Da purchased from Sigma Aldrich was used in this study. The stock solution of AHA $(0.2 \mathrm{~g} / \mathrm{L})$ was prepared by dissolving the powdered form AHA in $0.05 \mathrm{M}$ of sodium bicarbonate solution $\left(\mathrm{NaHCO}_{3}\right)$ to enhance its solubility [14]. Foulant solution was prepared by adding deionized (DI) water to the stock solution to obtain the desired concentration. The final AHA solution was adjusted to $\mathrm{pH} 8.5$ with dilute sodium hydroxide $(\mathrm{NaOH})$.

\section{Membranes}

Flat sheet polyvinylidene fluoride (PVDF) UF membranes 
with the MWCO of $150 \mathrm{kDa}$ (denoted as PVDF150) and 100 $\mathrm{kDa}$ (denoted as PVDF100) were adopted in the dead-end cell for fouling test using colloidal silica of 70-100 nm as model foulant. Other membranes employed in the dead-end cell are presented in Table II. A polycarbonate track-etch (PCTE) MF membrane of $5 \mu \mathrm{m}$ was chosen in the CFS cell

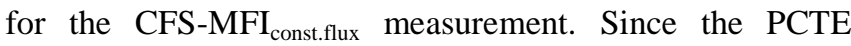
membranes are prepared using track-etch method, it has straight-through cylindrical pores rather than tortuous pores [15]. The main reason of adopting this type of membrane was to avoid retention of foulants on the surface of membrane installed into the CFS cell. It was believed that no depth-filtration would possibly happen in view of all foulants would pass to the permeate side via the straight-through pores [7]. The wettability of all membranes was measured using EasyDrop contact angle measuring instrument (KRÜSS $\mathrm{GmbH}$, Hamburg) based on the standard sessile drop method.

\section{RESUlTS AND DISCUSSION}

\section{A. Crossflow Hydrodynamic}

The plot for determining $\mathrm{MFI}_{\text {const.flux }}$ and CFS-MFI const.flux $_{\text {. }}$ under constant flux filtration mode is summarized in Table III. From Table III, the consistently lower values of CFS-MFI $_{\text {const.flux }}$ than the MFI $_{\text {const.flux values indicated that }}$ crossflow hydrodynamic effect played a dominant role in simulating the crossflow filtration effect as in RO system. Under crossflow filtration mode, the hydrodynamic shear force generated would help to reduce the effect of fouling by preventing foulants to be deposited on the membrane surface [16]-[18]. These findings were supported by Sim et al. [8] who found that the values of CFS-MFI const.flux $_{\text {obtained }}$ through a UF membrane were lower than that of $\mathrm{MFI}_{\text {const.flux }}$ with differences ranging from $5 \%$ to $38 \%$.

\section{B. Foulant Concentration}

Table IV compares the values of $\mathrm{MFI}_{\text {const.flux }}$ filtering colloidal silica of various solutions using two different types of UF membranes (i.e. PVDF150 and PVDF100 membranes). Consistent trends were observed for all the values of $\mathrm{MFI}_{\text {const.flux }}$, whereby a high concentration of colloidal silica yielded a high value of $\mathrm{MFI}_{\text {const.flux }}$ The increase of $\mathrm{MFI}_{\text {const.flux }}$ was mostly caused by particle depositions on the membrane surface. A higher rate of particle deposition onto the membrane was anticipated when a higher feed particle concentration was adopted. This is because a high particle concentration promotes the increase in the rate of convective transport of particles towards the membrane surface [19]. In addition, when the cumulative amount of deposited colloids increases, the hydraulic resistance of feedwater to flow through the compressed fouling layer would significantly increase and subsequently yields a high value of fouling index [20]. Moreover, the fouling behaviour is often accelerated when the load of particles deposited on membrane increases with filtration time [18], [21], [22]. Similar proportional trends are observed for the foulants of $22 \mathrm{~nm}$ colloidal silica and Aldrich humic acid (not shown in article).

\section{Foulant Particle Sizes}

Table $\mathrm{V}$ presents the values of $\mathrm{MFI}_{\text {const.flux }}$ for different particles sizes of colloidal silica foulants tested using PVDF100 membrane. The $\mathrm{MFI}_{\text {const.flux }}$ of the large polydispersed colloidal silica $(70-100 \mathrm{~nm})$ was consistently higher than that of smaller counterpart $(22 \mathrm{~nm})$ for all the concentrations studied. The results were in a good agreement with the research conducted by Song et al. [23]. They reported that higher fouling potential was obtained when filtering the feedwater containing broader particle sizes of polydispersed colloidal silica. This is because polydispersed particles are responsible to increase the effective depth of the cake layer formed, and hence create a higher resistance than those of the monodispersed particles of smaller size. Since larger particles are susceptible to much greater hydraulic drag force than those of small particles, it is suspected that significant compression of the fouling layer had occurred when large particles are used [24] and subsequently resulted in high values of $\mathrm{MFI}_{\text {const.flux }}$ [20].

\section{Membrane Resistance}

Membrane resistance quantifies permeability in terms of surface porosity, tortuosity, pore size and membrane thickness. In order to demonstrate the effect of membrane resistance on the $\mathrm{MFI}_{\text {const.flux }}$, the values of $\mathrm{MFI}_{\text {const.flux }}$ measured for the solutions of colloidal silica $(70-100 \mathrm{~nm})$ using PVDF150 and PVDF100 membrane is presented in Table IV. The measured $\mathrm{MFI}_{\text {const.flux }}$ values ranged from 290-11680 s/L $\mathrm{L}^{2}$. The fouling indices for the membranes with large membrane resistance had a higher value of $\mathrm{MFI}_{\text {const.flux }}$ than those of small membrane resistance (i.e. PVDF150). For instances, the fouling indices obtained for PVDF100 membrane were higher than that of PVDF150. It is generally accepted that membrane with a higher membrane resistance result in a much higher resistance of flow. Consequently, this may cause an increase in the TMP on the dead-end cell.

TABLE II: THE PROPERTIES OF MEMBRANE

\begin{tabular}{|c|c|c|c|c|c|}
\hline Membrane & Material & $\begin{array}{l}\text { Pore size } \\
\text { /MWCO }\end{array}$ & $\begin{array}{c}\text { Membrane resistance, } \\
R_{m} \times 10^{12}\left(\mathrm{~m}^{-1}\right) \\
\end{array}$ & $\begin{array}{c}\text { Contact angle, } \\
\theta\left(\left(^{\circ}\right)\right. \\
\end{array}$ & Manufacturer \\
\hline $\begin{array}{c}\text { PCTE } \\
\text { (Use in CFS cell) }\end{array}$ & Polycarbonate track-etch & $5 \mu \mathrm{m}$ & - & $87.9( \pm 4.6)$ & $\begin{array}{l}\text { Membrane } \\
\text { Solutions }\end{array}$ \\
\hline PVDF150 & Polyvinylidene fluoride & $150 \mathrm{kDa}$ & 1.55 & $91.6( \pm 3.4)$ & Amfor Inc. \\
\hline PVDF100 & Polyvinylidene fluoride & $100 \mathrm{kDa}$ & 1.96 & $92.9( \pm 5.7)$ & Amfor Inc. \\
\hline PES30 & Polyether sulfone & $30 \mathrm{kDa}$ & 4.15 & $72.7( \pm 4.0)$ & Amfor Inc. \\
\hline PES10 & Polyether sulfone & $10 \mathrm{kDa}$ & 6.16 & $68.7( \pm 4.1)$ & Amfor Inc. \\
\hline PES NF1 & Polyether sulfone & $200-400 \mathrm{Da}$ & 45.56 & $31.1( \pm 5.8)$ & Amfor Inc. \\
\hline
\end{tabular}




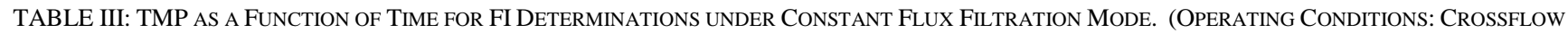
VELOCITY $=0.39 \mathrm{M} / \mathrm{s} ;$ FLUX $\left.=30.9 \mathrm{~L} / \mathrm{M}^{2} \mathrm{H}\right)$

\begin{tabular}{l}
\hline \hline Membranes and testing condition \\
\\
Membrane: PVDF, $100 \mathrm{kDa}$ \\
MWCO \\
Foulant: $70-100 \mathrm{~nm}$ colloidal \\
silica, $200 \mathrm{mg} / \mathrm{L}$ in solution.
\end{tabular}

Membrane: PES, 10 kDa MWCO Foulant: $22 \mathrm{~nm}$ colloidal silica, $200 \mathrm{mg} / \mathrm{L}$ in suspension.
Membrane: PES, 10 kDa MWCO Foulant: AHA, $10 \mathrm{mg} / \mathrm{L}$ in suspension.

CFS-MFI $_{\text {const.flux }}$
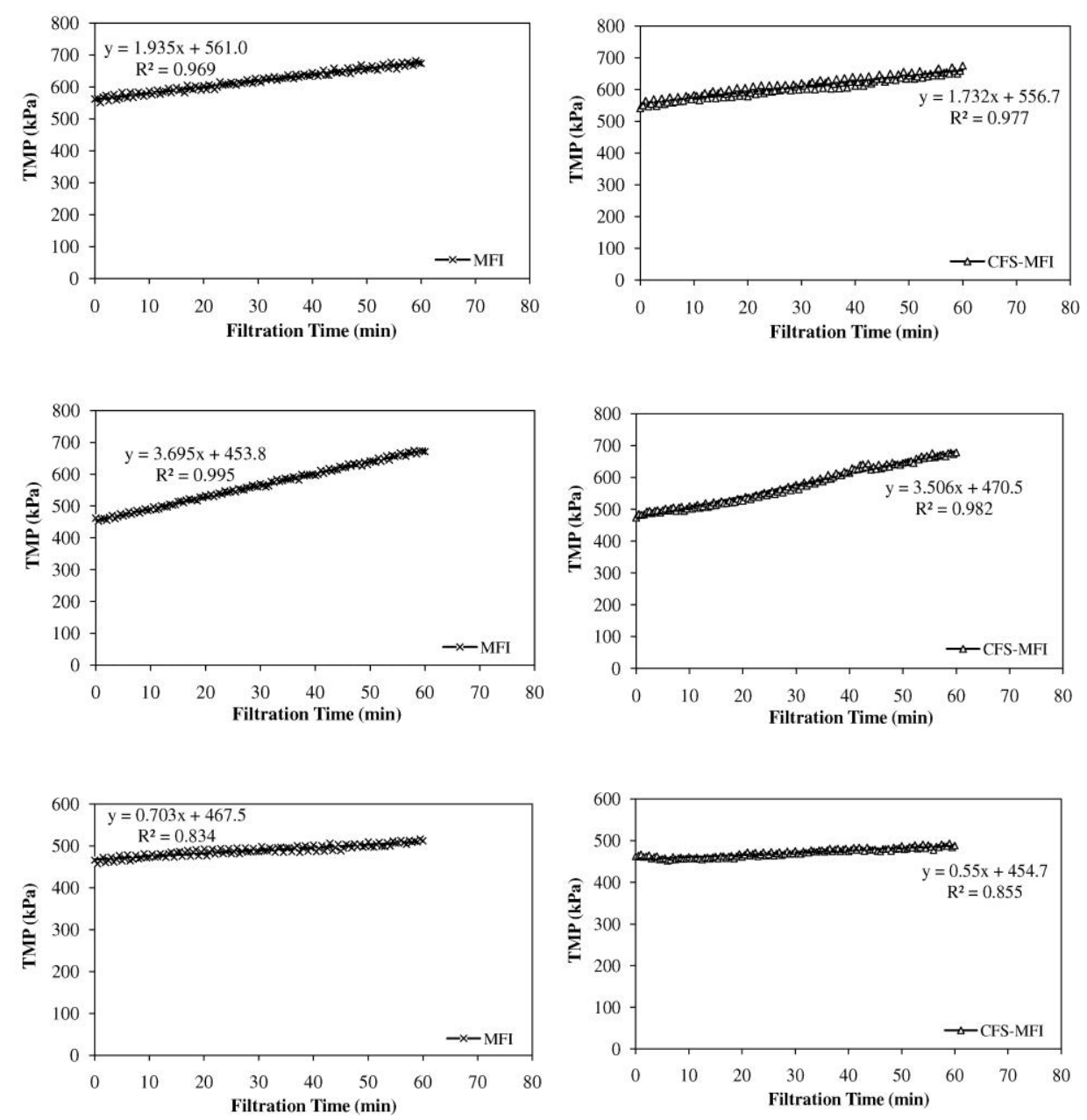

TABLE IV: COMPARISON OF MFI CONST.FLUX FOR DIFFERENT MEMBRANES TESTED WITH UP WATER AND COLLOIDAL SILICA (70-100 NM) SOLUTION OF 50, 100, AND $200 \mathrm{MG} / \mathrm{L}$

\begin{tabular}{ccc}
\hline \hline Concentration $(\mathrm{mg} / \mathrm{L})$ & PVDF150 & PVDF100 \\
\hline 0 (UP water) & $290( \pm 12)$ & $340( \pm 10)$ \\
50 & $3851( \pm 332)$ & $4062( \pm 260)$ \\
100 & $3950( \pm 389)$ & $6831( \pm 509)$ \\
200 & $4219( \pm 308)$ & $11680( \pm 290)$ \\
\hline \hline
\end{tabular}

TABLE V: COMPARISON OF MFI CONST.FLUX $_{\text {FOR DIFFERENT PARTICLES SIZE OF }}$ COLLOIDAL SILICA FOULANTS TESTED USING PVDF100 MEMBRANES

\begin{tabular}{ccc}
\hline \hline \multirow{2}{*}{ Concentration $(\mathrm{mg} / \mathrm{L})$} & \multicolumn{2}{c}{ Particles Size of Colloidal Silica } \\
\cline { 2 - 3 } & $70-100 \mathrm{~nm}$ & $22 \mathrm{~nm}$ \\
\hline 50 & $4062( \pm 260)$ & $3257( \pm 262)$ \\
100 & $6831( \pm 509)$ & $3620( \pm 303)$ \\
200 & $11680( \pm 290)$ & $3811( \pm 292)$ \\
\hline \hline
\end{tabular}

\section{CONCLUSION}

A series of experimental runs were carried out to investigate the performance of the fouling prediction devices. The following findings are drawn from this study:

1) It was found that the values of CFS-MFI const.flux $_{\text {obtained }}$ using a UF membrane for colloidal silica of 70-100 nm were lower than that of $\mathrm{MFI}_{\text {const.flux }}$. From the analysis results, the

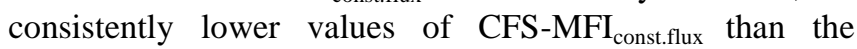

$\mathrm{MFI}_{\text {const.flux }}$ values indicated that crossflow hydrodynamic effect played a dominant role in simulating the crossflow filtration effect as in RO system.

2) Higher fouling indices are observed when high concentrations of feed foulants are used.

3) The $\mathrm{MFI}_{\text {const.flux }}$ of the large polydispersed colloidal silica $(70-100 \mathrm{~nm})$ was consistently higher than that of smaller counterpart $(22 \mathrm{~nm})$ for all the concentrations studied. This is because of polydispersed colloidal silica tends to create larger effective depth of the cake formed than those of the monodispersed colloidal silica.

4) The $M F I_{\text {const.flux }}$ of membrane with larger membrane resistance was higher than that of small membrane resistance.

The effect of crossflow hydrodynamic, foulant concentration, foulant particle sizes, and membrane resistance discussed in this study can provide valuable insights towards better understanding of the governing effects on the membrane fouling indices in a lab-scale device. Consequently, this study can promote the application of $\mathrm{MFI}_{\text {const.flux }}$ as a promising fouling prediction tool in controlling RO/NF fouling.

\section{ACKNOWLEDGMENT}

The authors wish to express their gratitude to Ministry of Higher Education Malaysia for the financial support under 
the grant of Top-Down Long Term Research Grant Scheme through project no. $4 \mathrm{~L} 804$.

\section{REFERENCES}

[1] A. Alhadidi, A. J. B. Kemperman, B. Blankert, J. C. Schippers, M Wessling, and W. G. J. van der Meer, "Silt density index and modified fouling index relation, and effect of pressure, temperature and membrane resistance," Desalination, vol. 273, no. 1, pp. 48-56, 2011.

[2] J. C. Schippers, and J. Verdouw, "The modified fouling index, a method of determining the fouling characteristics of water," Desalination, vol. 32, pp. 137-148, 1980.

[3] S. F. E. Boerlage, Scaling and Particulate Fouling in Membrane Filtration Systems, Taylor and Francis, 2001.

[4] S. F. E. Boerlage, M. D. Kennedy, M. P. Aniye, E. M. Abogrean, G. Galjaard, and J. C. Schippers, "Monitoring particulate fouling in membrane systems," Desalination, vol. 118, no. 1-3, pp. 131-142, 1998.

[5] S. G. Yiantsios and A. J. Karabelas, "The effect of colloid stability on membrane fouling," Desalination, vol. 118, no. 1-3, pp. 143-152, 1998.

[6] M. A. Javeed, K. Chinu, H. K. Shon, and S. Vigneswaran, "Effect of pre-treatment on fouling propensity of feed as depicted by the modified fouling index (MFI) and cross-flow sampler-modified fouling index (CFS-MFI)," Desalination, vol. 238, no. 1-3, pp. 98-108, 2009.

[7] S. S. Adham and A. G. Fane, Crossflow Sampler Fouling Index National Water Research Institute, California, USA, 2008.

[8] L. N. Sim, Y. Ye, V. Chen, and A. G. Fane, "Crossflow Sampler Modified Fouling Index Ultrafiltration (CFS-MFIUF)--An alternative Fouling Index," Journal of Membrane Science, vol. 360, no. 1-2, pp. 174-184, 2010.

[9] M. A. Javeed, D. E. Wiley, and A. G. Fane, "Development of the modified fouling index for the assessment of fouling propensity of the feed," School of Chemical Engineering and Industrial Chemistry, University of New South Wales, Australia, 2006.

[10] L. N. Sim, Y. Ye, V. Chen, and A. G. Fane, "Comparison of MFI-UF constant pressure, MFI-UF constant flux and Crossflow Sampler-Modified Fouling Index Ultrafiltration $\left(\mathrm{CFS}-\mathrm{MFI}_{\mathrm{UF}}\right)$," Water Research, vol. 45, no. 4, pp. 1639-1650, 2011.

[11] S. F. E. Boerlage, M. D. Kennedy, M. R. Dickson, D. E. Y. El-Hodali, and J. C. Schippers, "The modified fouling index using ultrafiltration membranes (MFI-UF): characterisation, filtration mechanisms and proposed reference membrane," Journal of Membrane Science, vol. 197, no. 1-2, pp. 1-21, 2002.

[12] A. J. Karabelas, "Critical assessment of fouling indices," MEDRC Series of R\&D Reports, 2003.

[13] K. Hong, S. Lee, S. Choi, Y. Yu, S. Hong, J. Moon, J. Sohn, and J. Yang, "Assessment of various membrane fouling indexes under seawater conditions," Desalination, vol. 247, no. 1-3, pp. 247-259, 2009.

[14] I. M. Adekunle, T. A. Arowolo, N. P. Ndahi, B. Bello, and D. A. Owolabi, "Chemical characteristics of humic acids in relation to lead, copper and cadmium levels in contaminated soils from South West Nigeria," Annals of Environmental Science, vol. 1, pp. 23-34, 2007.

[15] K. Nath, Membrane Seperation Process: Basic Concepts, Prentice-Hall of India Pvt. Limited, New Delhi, 2008.
[16] C. H. Koo, A. W. Mohammad, F. Suja', and M. Z. Meor Talib, "Use and development of fouling index in predicting membrane fouling - A Review," Separation and Purification Reviews, vol. 42, pp. 296-339, 2013.

[17] S. Phuntsho, H. K. Shon, S. Vigneswaran, and J. Cho, "Assessing membrane fouling potential of humic acid using flow field-flow fractionation," Journal of Membrane Science, vol. 373, no. 1-2, pp. 64-73, 2011.

[18] J. Kim and F. A. DiGiano, "Fouling models for low-pressure membrane systems," Separation and Purification Technology, vol. 68, no. 3, pp. 293-304, 2009.

[19] X. Zhu and M. Elimelech, "Colloidal fouling of reverse osmosis membranes: Measurements and fouling mechanisms," Environmental Science \& Technology, vol. 31, no. 12, pp. 3654-3662, 1997.

[20] C. H. Koo, A. W. Mohammad, F. Suja', and M. Z. Meor Talib, "Review of the effect of selected physicochemical factors on membrane fouling propensity based on fouling indices," Desalination, vol. 287, pp. 167-177, 2012.

[21] C. H. Koo, A. W. Mohammad, F. Suja, and M. Z. Meor Talib, "Setting-up of modified fouling index (MFI) and crossflow sampler-modified fouling index (CFS-MFI) measurement devices for NF/RO fouling," Journal of Membrane Science, vol. 435, pp. 165-175, 2013.

[22] B. Van der Bruggen, M. Mänttäri, and M. Nyström, "Drawbacks of applying nanofiltration and how to avoid them: A review," Separation and Purification Technology, vol. 63, no. 2, pp. 251-263, 2008

[23] L. Song, K. L. Chen, S. L. Ong, and W. J. Ng, "A new normalization method for determination of colloidal fouling potential in membrane processes," Journal of Colloid and Interface Science, vol. 271, no. 2 pp. 426-433, 2004

[24] N. N. Kramadhati, M. Mondor, and C. Moresoli, "Evaluation of the shear-induced diffusion model for the microfiltration of polydisperse feed suspension," Separation and Purification Technology, vol. 27, no. 1 , pp. 11-24, 2002

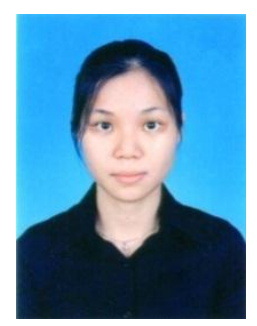

Charlene Koo is currently a lecturer in Universit Tunku Abdul Rahman (UTAR) of Kuala Lumpur campus. She received her B.Eng. degree in civil engineering and M.Eng. degree in civil engineering (environmental management) from the Technological University of Malaysia (UTM) in 2005 and 2006, respectively. She then worked as a process and design engineer in an environmenta specialist company in Johor Bahru for years before joining UTAR in 2009. In 2010, she pursued her doctoral studies at the National University of Malaysia (UKMalaysia) Recently, she has passed her doctoral examination and is expected to officially receive her scroll in October 2014. Her research interests are mainly focuse on water and wastewater treatment using membrane technology. Besides, she will also plan to venture into the water recycling and reclamation technology using membrane technology particularly for industrial applications. 
